\title{
Effects of a Caspase and a Calpain Inhibitor on Resting Energy Expenditures in Normal and Hypermetabolic Rats: a Pilot Study
}

\author{
P. G. VANA ${ }^{1}$, H. M. LAPORTE ${ }^{1}$, R. H. KENNEDY ${ }^{2}$, R. L. GAMELLI ${ }^{1}$, \\ M. MAJETSCHAK ${ }^{1,2}$
}

${ }^{1}$ Department of Surgery, Burn and Shock Trauma Research Institute, Loyola University Chicago, Stritch School of Medicine, Maywood, IL, USA, ${ }^{2}$ Department of Molecular Pharmacology and Therapeutics, Loyola University Chicago, Stritch School of Medicine, Maywood, IL, USA

Received September 21, 2015

Accepted January 22, 2016

On-line April 12, 2016

\section{Summary}

Several diseases induce hypermetabolism, which is characterized by increases in resting energy expenditures (REE) and whole body protein loss. Exaggerated protein degradation is thought to be the driving force underlying this response. The effects of caspase and calpain inhibitors on REE in physiological and hypermetabolic conditions, however, are unknown. Thus, we studied whether MDL28170 (calpain inhibitor) or z-VAD-fmk (caspase inhibitor) affect REE under physiological conditions and during hypermetabolism post-burn. Rats were treated five times weekly and observed for 6 weeks. Treatment was started $2 \mathrm{~h}$ (early) or $48 \mathrm{~h}$ (late) after burn. In normal rats, MDL28170 transiently increased REE to $130 \%$ of normal during week 2-4. z-VAD-fmk reduced REE by 20-25\% throughout the observation period. Within 14 days after burns, REE increased to $130 \pm 5 \%$. Whereas MDL28170/early treatment did not affect REE, MDL28170/late transiently increased REE to $180 \pm 10 \%$ of normal by week 4 post-burn. In contrast, with z-VAD-fmk/early REE remained between $90-110 \%$ of normal post-burn. z-VAD$\mathrm{fmk} /$ late did not affect burn-induced increases in REE. These data suggest that caspase cascades contribute to the development of hypermetabolism and that burn-induced hypermetabolism can be pharmacologically modulated. Our data point towards caspase cascades as possible therapeutic targets to attenuate hypermetabolism after burns, and possibly in other catabolic disease processes.

\section{Key words}

Resting energy expenditure • Burn • Hypermetabolism • Calpain - Caspase

\section{Corresponding author}

M. Majetschak, Burn and Shock Trauma Research Institute, Loyola University Chicago, Stritch School of Medicine, 2160 S. 1st Avenue, Maywood, IL 60153, USA. Fax: (708) 327-2813. E-mail: mmajetschak@luc.edu

Multiple disease processes, such as cancer, sepsis, trauma or burns, induce hypermetabolism, which is characterized by increases in resting energy expenditures (REE) and total body protein loss (Dev 2014, Madeddu et al. 2015, Cohen et al. 2015) The clinical consequences of hypermetabolism are profound and include muscle cachexia, increased morbidity and mortality and prolonged hospitalization and recovery periods (Pereira et al. 2005, Dev 2014, Madeddu et al. 2015, Cohen et al. 2015). Drugs that may attenuate the hypermetabolic response are currently not available. Such drugs, however, are highly desirable as they have the potential to improve outcomes.

In patients with burn injuries, increases in REE are proportional to the size and degree of the burn injury and persist for month to years, even after complete wound closure (Matsuda et al. 1987, Jeschke et al. 2011). Studies of muscle protein turnover after burn injuries in patients showed that both protein synthesis and 
degradation are significantly increased. As increases in protein breakdown exceeded increases in protein synthesis, exaggerated protein degradation appears to be the driving force underlying the development of hypermetabolism (Biolo et al. 2002, Chao et al. 2015). Thus, drugs that inhibit protein degradation could potentially attenuate net protein loss and increases in REE in hypermetabolic conditions. The specific contributions of major non-lysosomal proteolytic systems, such as the ubiquitin-proteasome pathway of protein degradation, the calpain or caspase system, to the development of post-burn hypermetabolism, however, are not well understood. We have shown previously that bortezomib, a FDA approved proteasome inhibitor, delayed increases in REE in a rat scald burn model when treatment was initiated $48 \mathrm{~h}$ after injury and reduced burn-induced REE when treatment was started within $2 \mathrm{~h}$ after injury (Vana et al. 2015). The latter, however, was associated with significantly increased mortality after burns (Vana et al. 2015). The effects of calpain and caspase inhibitors on REE after burns are unknown. Thus, we performed a pilot study to assess whether the calpain inhibitor MDL28170 and the pan-caspase inhibitor z-Valine-Alanine-Aspartate-fluoromethylketone (z-VAD-fmk) influence REE and body weight within a clinically relevant time frame in a rat scald burn model. MDL28170 is a cell-permeable calpain inhibitor that has been reported to possess neuroprotective effects in vivo (Kawamura et al. 2005, Li et al. 1998). z-VAD-fmk is an irreversible cell-permeable pan-caspase inhibitor with in vivo anti-apoptotic and anti-inflammatory effects (Graczyk 2002, Neviere et al. 2001).

All procedures were performed according to National Institutes of Health Guidelines for Use of Laboratory Animals and approved by the Loyola Institutional Animal Care and Use Committee and the Department of Defense Animal Care and Use Review Office. Male Sprague Dawley rats (325-375 g, Harlan, Indianapolis, IN) were anesthetized with $2.5 \%$ isoflurane, shaved and placed into a template that exposes a dorsal body area corresponding to $30 \%$ of their total body surface area (TBSA). A full thickness burn was then induced by immersion of the dorsal skin into boiling water as previously described (Wong et al. 2014, Vana et al. 2015). Sham animals were treated as described, except that their dorsal surface was immersed in tepid water. Burned animals were then resuscitated with crystalloid solution i.p. as per the Parkland formula ( $4 \mathrm{ml} / \mathrm{kg}$ per percent TBSA) over the first $48 \mathrm{~h}$ after burn injury.
Animals were treated with vehicle ( $0.4 \mathrm{ml}$ normal saline), $10 \mathrm{mg} / \mathrm{kg}$ MDL28170 (Enzo Life Sciences, Farmingdale, NY and Cayman Chemical, Ann Arbor, MI) or $1 \mathrm{mg} / \mathrm{kg}$ z-VAD-fmk (Enzo Life Sciences, Santa Cruz Biotechnology, Dallas, TX) in $0.4 \mathrm{ml}$ of normal saline i.p. five times weekly. Treatment was started $48 \mathrm{~h}$ after sham injury, and $2 \mathrm{~h}$ (early) or $48 \mathrm{~h}$ (late) after burn. The doses of MDL28170 and z-VAD-fmk were selected based on previous animal studies in which these drugs were found to be safe and effective (Rodriguez et al. 1996, Equils et al. 2009, Yu and Geddes 2007). Body weight and REE were measured weekly throughout a six week observation period. REE is expressed as \% of normal (day 0 ) and was measured with indirect calorimetry, as described previously (Wong et al. 2014, Vana et al. 2015). At the end of the observation period, animals were euthanized. Data, presented as mean \pm SEM, were analyzed with twoway ANOVA with Holm-Sidak's multiple comparisons test. Survival between groups was compared with the Log-rank test. Statistical analyses were calculated with the GraphPad Prism program (GraphPad Software). A two-tailed $p<0.05$ was considered significant.

The effects of MDL28170 ( $\mathrm{n}=5)$ and $\mathrm{z}$-VADfmk $(n=5)$ treatment on body weight and REE in animals after sham procedure (vehicle treatment $-\mathrm{n}=9$ ) are shown in Figure 1. All except one animal after sham procedure survived the observation period and showed normal behavior and food intake. The single animal that died after sham procedure was vehicle treated. Post mortem necropsy did not reveal any macroscopic abnormalities. There were no statistically significant differences in body weights between groups before sham injury (day 0). Body weights increased continuously and were indistinguishable among the groups (Fig. 1A). In vehicle treated animals, REE remained constant throughout the observation period (105 $\pm 3 \%-114 \pm 7 \%$; Fig. 1B). With MDL28170 treatment, however, REE increased transiently to $131 \pm 4 \%$ on day 14 and normalized by day 42 (Fig. 1B). In contrast, REE were significantly reduced on day $7(76 \pm 3 \%)$ and on days $21(84 \pm 2 \%)$ $42(83 \pm 3 \%$; Fig. 1B) with z-VAD-fmk treatment.

After burn injury and vehicle treatment $(n=10)$, body weights slightly increased within the observation period (Fig. 2A). As compared with vehicle treated animals after sham procedure (Fig. 1A), body weights were significantly reduced on days 7-42 after burn injury and vehicle treatment. While early $(n=6)$ and late $(n=5)$ $z$-VAD-fmk treatment did not affect body weight after burns, MDL28170 early $(\mathrm{n}=6 ; \mathrm{p}<0.5$ vs. vehicle on 
day 14) and late $(n=5 ; p<0.05$ vs. vehicle on days 7,14 and 28 ) treatment transiently reduced body weights after burns, as compared with vehicle treated animals (Fig. 2A).
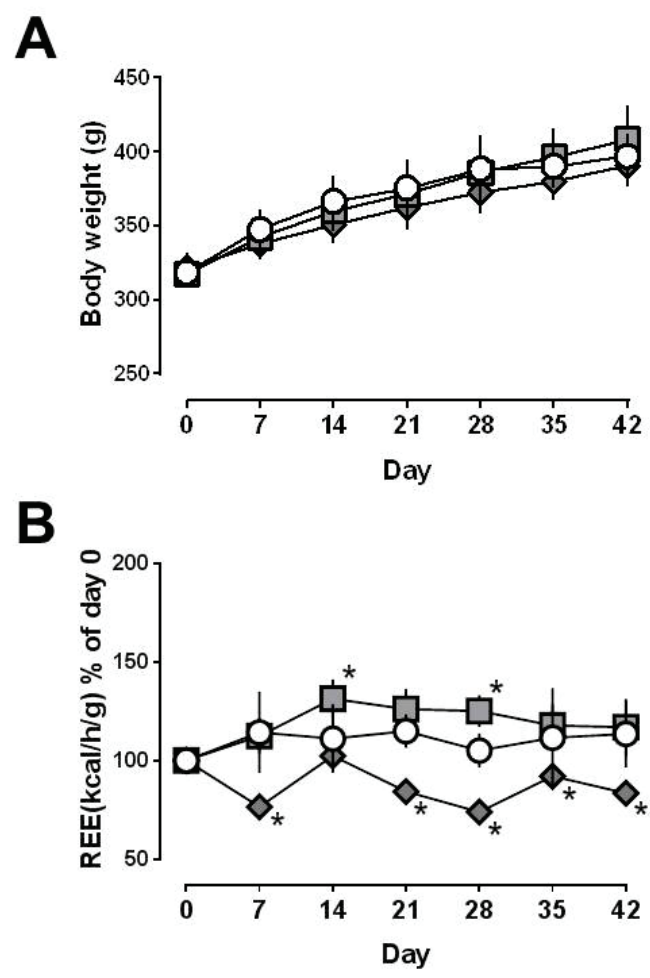

Fig. 1. Effects of MDL28170 and z-VAD-fmk on body weights (A) and resting energy expenditures (B) in normal (sham) rats. A. Body weight (g). B. Resting energy expenditure (REE; $\mathrm{kcal} / \mathrm{h} / \mathrm{g}$ ) in \% of normal (day 0 ). Open circles: vehicle treatment $(n=9-10)$. Grey squares: MDL28170 treatment $(n=5)$. Grey diamonds: $z-V A D-f m k$ treatment $(n=5)$. Data are mean \pm SEM. $* p<0.05$ vs. vehicle treated animals.

REE increased within 14 days after burn injury and vehicle treatment to $130 \pm 5 \%$ and remained elevated thereafter (Fig. 2B). This increase in REE after burns is consistent with our previous observations in this model (Wong et al. 2014, Vana et al. 2015) and with the expected REE of $129 \%$ after a comparable burn injury in humans (Jones 1993, Carlson et al. 1992). While early treatment with MDL28170 did not affect REE after burns, late MDL28170 treatment transiently enhanced burn-induced increases in REE, which peaked at $184 \pm 10 \%$ on day 21 ( $<<0.05$ vs. vehicle on days 7 and 21-35) and decreased to $155 \pm 9 \%$ on day 42 ( $p>0.05$ vs. vehicle). In contrast, with early $z-V A D-f m k$ treatment, REE remained between $82 \pm 4 \%$ - $109 \pm 9 \%$ throughout the six week observation period. As compared with vehicle treated animals, REE were significantly reduced on days $7,21,28$ and 42 after burns with early
z-VAD-fmk treatment. After burn injury, all animals in the vehicle and MDL28170 treatment groups survived the observation period. One animal after burn and early z-VAD-fmk treatment and one animal after burn and late z-VAD-fmk treatment died during the observation period ( $>0.05$ vs. vehicle and MDL28170 treatment).

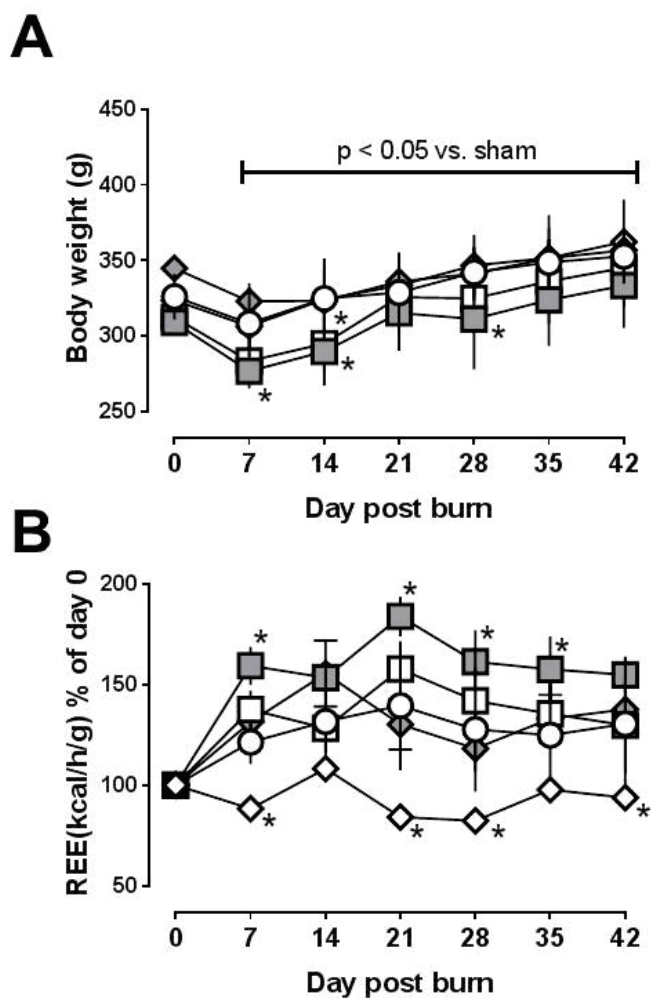

Fig. 2. Effects of MDL28170 and z-VAD-fmk on body weights (A) and resting energy expenditures (B) after burn injury. A. Body weight $(\mathrm{g})$. Signifcant differences between vehicle treated animals after sham procedure (please see Fig. 1A) and after burn are shown. B. Resting energy expenditure (REE; kcal/h/g) in \% of normal (day 0). Open circles: vehicle treatment $(n=10)$. Open squares: MDL28170 early treatment $(n=6)$. Grey squares: MDL28170 late treatment $(n=5)$. Open diamonds: $z-V A D-f m k$ early treatment $(n=5-6)$. Grey diamonds: z-VAD-fmk late treatment $(n=4-5)$. Data are mean \pm SEM. $* p<0.05$ vs. vehicle treated animals after burn injury.

Several lines of evidence suggest that caspase activities are significantly increased in skeletal muscle after burns, which may contribute to metabolic protein turnover (Duan et al. 2009, Yasuhara et al. 2000, Lee et al. 2011, Wong et al. 2014). Thus, the finding of the present pilot study that z-VAD-fmk prevented burninduced increases in REE supports the concept that caspase activation contributes to the development of postburn hypermetabolism. Furthermore, our observation points towards caspase cascades as potential therapeutic target after burns, and possibly in other muscle wasting disease processes. 
Similar to our previous observation that proteasome inhibition resulted in distinct effects when treatment was initiated early and late after burns, z-VAK-fmk prevented increases in REE after burns only when treatment was initiated early (Vana et al. 2015). This further supports the notion that events during the initial hypodynamic-hypometabolic phase after burns (ebb or shock phase, Wolfe 1981, Tredget and Yu 1992) initiate and determine the hypermetabolic response weeks after injury.

Interestingly, MDL28170 and z-VAD-fmk treatment resulted in similar effects on REE in animals with burn-induced hypermetabolism and in normal (sham injured) animals. In contrast, we could not observe any changes in REE after proteasome inhibition in normal animals previously (Vana et al. 2015). As caspase and calpain mediated protein cleavage are known to alter substrate availability of the proteasome (Pasiakos and Carbone 2014), these data may suggest an important role of the calpain and caspase systems in the regulation of normal and pathological protein and energy metabolism.

In context of the existing information on the roles of calpains in muscle wasting diseases, the observation that MDL28170 increased REE after burns appears paradoxical and requires further investigation (Costelli et al. 2005, Smith et al. 2008). As for any pharmacological intervention, however, we cannot exclude that off-target effects of MDL28170 could explain the observed transient increases in REE. Furthermore, as we tested only a single dosing regimen for MDL28170 and z-VAD-fmk and terminated the experiments at 6 weeks after injury, we can currently not comment on their dose-effect relationships and on possible effects of these drugs beyond this time period.

In conclusion, the findings from this pilot study further suggest that caspase cascades may contribute to the development of hypermetabolism. Our observations indicate that burn-induced hypermetabolism can be pharmacologically modulated and point towards caspase cascades as possible therapeutic targets to attenuate hypermetabolism after burns, and possibly in other catabolic disease processes.

\section{Conflict of Interest}

There is no conflict of interest.

\section{Acknowledgements}

This research was made possible by a grant that was awarded and administered by the U.S. Army Medical Research and Materiel Command (USAMRMC) and the Telemedicine and Advanced Technology Research Center (TATRC), at Fort Detrick, MD, under Contract Number W81XWH1110559. The views, opinions and/or findings contained in this research are those of the author(s) and do not necessarily reflect the views of the Department of Defense and should not be construed as an official DoD/Army position, policy or decision unless so designated by other documentation. No official endorsement should be made. This work was also supported in part by National Institutes of Health Grant NIHT32GM008750 and the Dr. Ralph and Marian Falk Medical Research Trust.

This research has been presented, in part, at the $17^{\text {th }}$ Congress of the International Society for Burn Injuries, Sydney, Australia, October 2014.

\section{References}

BIOLO G, FLEMING RY, MAGGI SP, NGUYEN TT, HERNDON DN, WOLFE RR: Inverse regulation of protein turnover and amino acid transport in skeletal muscle of hypercatabolic patients. $J$ Clin Endocrinol Metab 87: 3378-3384, 2002.

CARLSON DE, CIOFFI WG JR, MASON AD JR, MCMANUS WF, PRUITT BA JR: Resting energy expenditure in patients with thermal injuries. Surg Gynecol Obstet 174: 270-276, 1992.

CHAO T, HERNDON DN, PORTER C, CHONDRONIKOLA M, CHAIDEMENOU A, ABDELRAHMAN DR, BOHANON FJ, ANDERSEN C, SIDOSSIS LS: Skeletal muscle protein breakdown remains elevated in pediatric burn survivors up to one-year post-injury. Shock 44: 397-401, 2015.

COHEN S, NATHAN JA, GOLDBERG AL: Muscle wasting in disease: molecular mechanisms and promising therapies. Nat Rev Drug Discov 14: 58-74, 2015.

COSTELLI P, REFFO P, PENNA F, AUTELLI R, BONELLI G, BACCINO FM: Ca(2+)-dependent proteolysis in muscle wasting. Int J Biochem Cell Biol 37: 2134-2146, 2005. 
DEV R: The assessment and management of cancer cachexia: hypogonadism and hypermetabolism among supportive and palliative care patients. Curr Opin Support Palliat Care 8: 279-285, 2014.

DUAN H, CHAI J, SHENG Z, YAO Y, YIN H, LIANG L, SHEN C, LIN J: Effect of burn injury on apoptosis and expression of apoptosis-related genes/proteins in skeletal muscles of rats. Apoptosis 14: 52-65, 2009.

EQUILS O, MOFFATT-BLUE C, ISHIKAWA TO, SIMMONS CF, ILIEVSKI V, HIRSCH E: Pretreatment with pancaspase inhibitor (Z-VAD-FMK) delays but does not prevent intraperitoneal heat-killed group B Streptococcus-induced preterm delivery in a pregnant mouse model. Infect Dis Obstet Gynecol 2009: 749432, 2009.

GRACZYK PP: Caspase inhibitors as anti-inflammatory and antiapoptotic agents. Prog Med Chem 39: 1-72, 2002.

JESCHKE MG, GAUGLITZ GG, KULP GA, FINNERTY CC, WILLIAMS FN, KRAFT R, SUMAN OE, MLCAK RP, HERNDON DN: Long-term persistance of the pathophysiologic response to severe burn injury. PLoS One 6: e21245, 2011.

JONES LK: Resting energy expenditure in patients with thermal injuries. J Parenter Enteral Nutr 17: 94-96, 1993.

KAWAMURA M, NAKAJIMA W, ISHIDA A, OHMURA A, MIURA S, TAKADA G: Calpain inhibitor MDL 28170 protects hypoxic-ischemic brain injury in neonatal rats by inhibition of both apoptosis and necrosis. Brain Res 1037: 59-69, 2005.

LEE HY, KANEKI M, ANDREAS J, TOMPKINS RG, MARTYN JA: Novel mitochondria-targeted antioxidant peptide ameliorates burn-induced apoptosis and endoplasmic reticulum stress in the skeletal muscle of mice. Shock 36: 580-585, 2011.

LI PA, HOWLETT W, HE QP, MIYASHITA H, SIDDIQUI M, SHUAIB A: Postischemic treatment with calpain inhibitor MDL 28170 ameliorates brain damage in a gerbil model of global ischemia. Neurosci Lett 247: 17-20, 1998.

MADEDDU C, MANTOVANI G, GRAMIGNANO G, MACCIO A: Advances in pharmacologic strategies for cancer cachexia. Expert Opin Pharmacother 16: 2163-2177, 2015.

MATSUDA T, CLARK N, HARIYANI GD, BRYANT RS, HANUMADASS ML, KAGAN RJ: The effect of burn wound size on resting energy expenditure. J Trauma 27: 115-118, 1987.

NEVIERE R, FAUVEL H, CHOPIN C, FORMSTECHER P, MARCHETTI P: Caspase inhibition prevents cardiac dysfunction and heart apoptosis in a rat model of sepsis. Am J Respir Crit Care Med 163: 218-225, 2001.

PASIAKOS SM, CARBONE JW: Assessment of skeletal muscle proteolysis and the regulatory response to nutrition and exercise. IUBMB Life 66: 478-484, 2014.

PEREIRA C, MURPHY K, JESCHKE M, HERNDON DN: Post burn muscle wasting and the effects of treatments. Int J Biochem Cell Biol 37: 1948-1961, 2005.

RODRIGUEZ I, MATSUURA K, ODY C, NAGATA S, VASSALLI P: Systemic injection of a tripeptide inhibits the intracellular activation of CPP32-like proteases in vivo and fully protects mice against Fas-mediated fulminant liver destruction and death. $J$ Exp Med 184: 2067-2072, 1996.

SMITH IJ, LECKER SH, HASSELGREN PO: Calpain activity and muscle wasting in sepsis. Am J Physiol Endocrinol Metab 295: E762-E771, 2008.

TREDGET EE, YU YM: The metabolic effects of thermal injury. World J Surg 16: 68-79, 1992.

VANA PG, LAPORTE HM, WONG YM, KENNEDY RH, GAMELLI RL, MAJETSCHAK M: Proteasome inhibition after burn injury. J Burn Care Res in press 2015.

WOLFE RR: Review: acute versus chronic response to burn injury. Circ Shock 8: 105-115, 1981.

WONG YM, LA PORTE HM, SZILAGYI A, BACH HH, KE-HE L, KENNEDY RH, GAMELLI RL, SHANKAR R, MAJETSCHAK M: Activities of nonlysosomal proteolytic systems in skeletal and cardiac muscle during burninduced hypermetabolism. J Burn Care Res 35: 319-327, 2014.

YASUHARA S, PEREZ ME, KANAKUBO E, YASUHARA Y, SHIN YS, KANEKI M, FUJITA T, MARTYN JA: Skeletal muscle apoptosis after burns is associated with activation of proapoptotic signals. Am J Physiol Endocrinol Metab 279: E1114-E1121, 2000.

YU CG, GEDDES JW: Sustained calpain inhibition improves locomotor function and tissue sparing following contusive spinal cord injury. Neurochem Res 32: 2046-2053, 2007. 